\title{
Nutrition security and the importance of international trade to meet population-level energy and nutrient requirements
}

\author{
J.I. Macdiarmid ${ }^{1}$, H. Clark ${ }^{2}$, S. Whybrow ${ }^{1}$, H. de Ruiter ${ }^{1}$ and G. McNeill ${ }^{2}$ \\ ${ }^{1}$ The Rowett Institute and ${ }^{2}$ Institute of Applied Health Sciences, University of Aberdeen, AB25 2ZD.
}

National nutrition security exists when the supply of energy and nutrients is sufficient to meet population-level dietary requirements. This supply depends on the domestic production and the international trade of food. The aim of this study was to assess nutrition security in the UK and calculate the contribution of energy and nutrients from imported food to meet population-level dietary requirements in the UK.

Energy and nutrients supplies were estimated using FAO food balance sheets (FBS) data ${ }^{(1)}$. These data comprise the annual supply of 85 groups of food commodities, which are aggregates of many food items. These 85 groups were disaggregated and mapped to 701 foods in the UK food composition tables ${ }^{(2)}$, which were used to estimate the supply of energy and nutrients. All data were converted to represent the food as eaten and adjusted for household waste. The data were based on an average of three years supply data from the FBS (2009-2011) and separated into the proportion of nutrients from domestic production (production minus exports and variation in domestic stocks), imported and exported food. This was compared with population-level dietary requirements, from dietary reference values and recommendations, which were weighted to take into account differences in requirements by age and sex of the population.

The total supply of nutrients in the UK was sufficient to meet population-level energy and nutrient requirements, with the exception of fibre (non-starch polysaccharides) (see figure). This reflects the supply of highly refined cereal products. It was estimated that if all cereal- based products were wholegrain there would be sufficient fibre to meet the population requirements. The UK rely on imports for energy, iron and zinc, while domestic supply of vitamins A and C was marginal. Vegetables and fruit were the main sources of vitamin A and C, respectively, with approximately $80 \%$ of vitamin C from fruit and $57 \%$ of vitamin A from vegetables coming from imports, the majority of which come through Europe. For food such as free sugars and fats the supply was much greater than maximum recommendations.
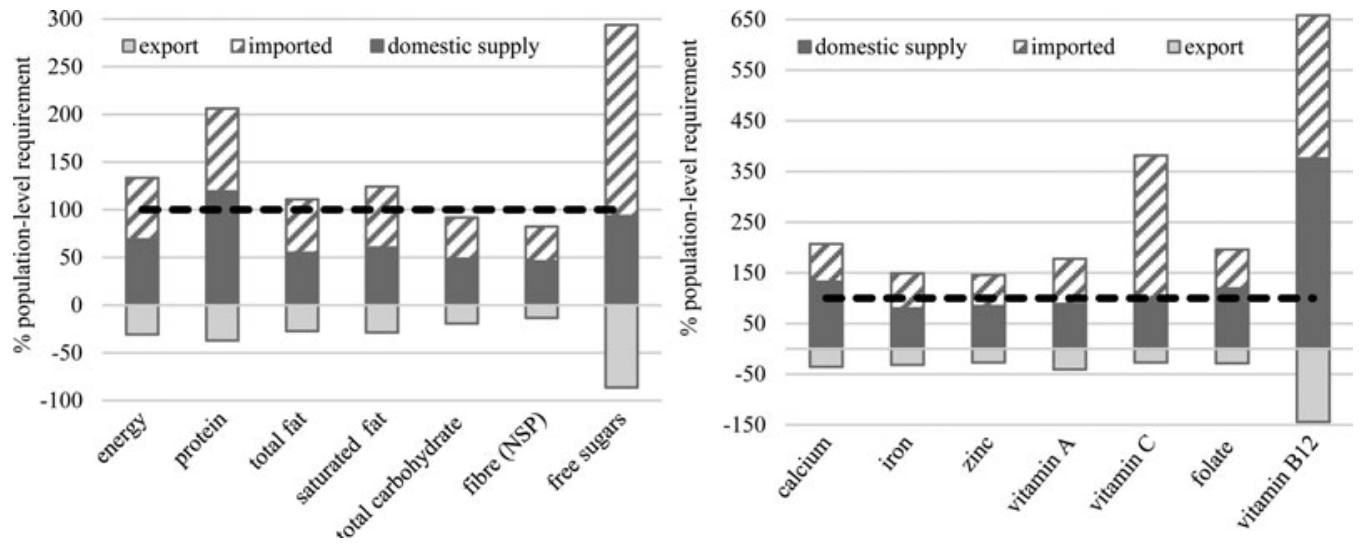

These data show the importance of going beyond food security to consider the nutrient quality of the food supply within a country. It also highlights the reliance on international trade to achieve the required nutrient supply and the globalisation of the food system.

$1 \mathrm{FAO} / \mathrm{UN}$ food balance sheet (2018) http://www.fao.org/economic/ess/fbs/en/.

2 McCance and Widdowson's The composition of foods (2015) Seventh Edition. 